\title{
Coping mechanisms used by students in open and distance learning (ODL) in response to stressful events. A case study of the Zimbabwe Open University (ZOU)
}

\author{
Nyatsanza, Taurai $\mathrm{D}^{1}$, Mtezo, Justina $\mathrm{Z}^{2}$ \\ ${ }^{1}$ (Student Management, Harare Region/ Zimbabwe Open University Zimbabwe) \\ ${ }^{2}$ (Administration/ Harare Region, Zimbabwe Open University, Zimbabwe)
}

\begin{abstract}
ODL students suffer from a lot of stress because of the many competing responsibilities they have to shoulder. With limited support from tutors, the university administration like in the conventional system and the rigors of balancing work, married life and studying, ODL students have to increasingly rely on coping mechanisms to deal with these stressful events. As a result they have to develop these coping strategies as buffers A qualitative study was done using various concepts from coping models and theories. A lot has been written about coping mechanisms used by students in the western world to manage stressful situations they found themselves in during their academic life. What coping mechanisms do students do ODL students in Zimbabwe at Harare Region of the ZOU use? Data was collected from twenty purposively selected students from different faculties in the Harare Region of the Zimbabwe Open University. An analysis of the findings identified the coping mechanisms used by students and what the students expect the institution to do to assist in alleviating their stress.
\end{abstract}

Keywords: (Coping mechanisms, coping models Open distance learning, stressful event)

\section{Introduction}

Open and distance learning students face many challenges in their education (Van Dorp and Monteros 2010). These challenges relate to family responsibilities, work, failure to cope with studies, failure to balance finances and other social responsibilities. These challenges trigger stressful events /situations that if not managed may negatively affect academic performance and progress.ODL students need to adopt coping mechanisms to help them manage succeed in education. The stressful events become objective and subjective burdens, which are detrimental to physical and mental well being of the student. While some studies provide valuable coping strategies by students in conventional institutions and some distance learners, a closer look at the Zimbabwean context will provide home grown strategies for coping with stressful situations. Some of the objectives of trying to find coping mechanisms used by ODL students are to:

- Determine the most appropriate coping mechanisms used by ODL students.

- Make the responsible authorities in the Ministry of Higher Education, and ODL institutions develop appropriate interventions aimed at enabling the students to cope with the stressful events in their education.

- Find out what assistance the students expect from the institution.

- Find out if there is a link between personal traits and use of known coping mechanisms.

\section{Background to study}

The Zimbabwe Open University was established in 1993 as a college of distance education under the University of Zimbabwe and got its charter in 1999. This was in response to the high demand for Tertiary Education by the majority of citizens who had been excluded by the bottle-neck system used before independence. The target population was (and remains largely so today) mature adults who are working or engaged in activities that do not allow them to enrol for fulltime programmes. An extensive body of literature underscores that providing education to ODL students has challenges for students, tutors and administrators (Baider, Cooper and De-Nour, 1996, D'Cruz, 2002 ) In Zimbabwe, ODL as a mode of education is still in its infancy compared to other parts of the world. It has inherently been characterised by poor funding, lack of information on available support systems, negative attitudes from programme administrators and employers, and neglect of Zimbabwean value system which the students grew up in. This system provided for psycho-social support (Chimedza undated).The students also face pressure from the rapidly growing global market which expects employable and entrepreneurial graduates. The other common challenges faced by ODL students include:

- Taking responsibility for ones' learning

- Decision making 
- Accessing relevant learning materials

- $\quad$ Limited student - tutor interaction

- $\quad$ Space to do academic work

- Balancing academic work and non-academic responsibilities

- Managing change from conventional learning to ODL (Maunganidze in Chimedza undated)

Despite stressful situations triggered by the above, some students do extremely well in their studies. How do they manage to deal with these stressful situations so that their academic work is not negatively affected. This research focused on establishing coping mechanisms used by students in ODL in Harare at the Zimbabwe Open University.

\section{Research Questions}

- How do students deal with stressful events/ situations?

- Which coping mechanism is mostly used in managing stressful events?

- Is there a relationship in the use of any coping mechanism and the demographic variables?

- What support does the institution offer to students in managing stressful situations?

Although the students face these many challenges, little attention has been focused on how ODL students are managing to pull through. Management of these inadequacies by the students is very important and has resulted in these ODL education programmes contributing much to the national development of many countries. The purpose of the study was to determine how ODL students at Zimbabwe Open University in Harare manage stressful events/situations.

The findings of this study will contribute to knowledge about how ODL students cope with stressful events and results obtained in the research will be used to improve the management of ODL students in Zimbabwe. This knowledge will also lead to a new understanding of coping mechanisms to be used by students in general.

\subsection{Theoretical Framework / conceptual Framework}

\section{Literature Review}

The theoretical framework for this study was based on the cognitive theory of coping developed by Folkman and Lazarus (1988). This theory was selected because it links the constructs central to this study. The theory posits that portions of an individual's knowledge acquisition can be directly related to observing others within the context of social interactions, experiences, and outside media influences. People do not learn new behaviours solely by trying them and either succeeding or failing, but rather, the survival of humanity is dependent upon the replication of the actions of others. Coping as a result is a survival technique.

There are three meta-theoretical assumptions: transaction, process, and context. It is assumed, first, that emotions occur as a specific encounter of the person with the environment and that both exert a reciprocal influence on each other; second, that emotions and cognitions are subject to continuous change; and third, that the meaning of a transaction is derived from the underlying context, i.e., various attributes of a natural setting determine the actual experience of emotions and the resulting action tendencies.

Literature identifies relevant concepts related to coping mechanisms used by students in ODL. These concepts include theories used to adapt coping mechanisms used by students in dealing with stressful events. The study will review literature from different authors who have done research on coping mechanisms or similar concepts. Literature was not limited to ODL students only but also covered conventional students.

\subsection{The Concept of Coping}

Folkman and Lazarus (1988) defined coping as changing cognitive and behavioural effort to manage specific external and/ or internal demands that are seen as taxing or exceeding the resources of the person. Muersing (1996), Puhl and Brownell (2003) defined coping as any behaviour or thought process unconsciously brought into use by an individual to protect himself/herself against painful or anxiety provoking feelings, impulses and perceptions. This definition includes defensive coping strategies. Coping is primarily a psychological concept and although there are many definitions, all share the same concept that of a struggle with conflicts, emotions and demands. In this paper coping is be defined as the process through which the student successfully manages stressful events/situations that are seen as taxing or exceeding the available resources.

\subsection{Assessment of coping}

Two approaches have been used in the assessment of coping, these are, episodic or situational assessment and draft or dispositional assessment (Buettner, 1990). He is of the opinion that tract measures of coping refer to an individual's habitual or particular way to deal with tracts or dispositions aligned to the 
personality of that individual. Baldwin, (1990) referred to tract assessment as an enduring property of a person or a disposition to respond in a certain way under a variety of circumstances. Episodic measures of coping deal with the strategies individuals actually use in a particular stressful situation (Lazarus and Folkman 1988).

Puhl and Brownell, (2003) pointed out that the measurements of coping have predictive values with respect to the coping process. Since coping is a process, it changes over time. People use an emotion-focused strategy or vice versa. Lazarus and Folkman (1988), Taylor (1986), Tomaka and Blascovich (1994), came up with a coping measuring instrument. They used this instrument to measure the coping mechanism used by administrators of social and educational institutions. The ways of coping instrument had eight coping mechanisms which they called scales. They were namely cognitive coping, distancing, self-controlling, seeking social support, accepting responsibility, escape-avoidance, playful problem solving and positive reappraisal.

\subsection{Coping Mechanisms Used in Education}

EUA (2008), Geser (2007), Kauffman (2010), Van Dorp and Monteros (2010), highlighted that stressful events will always be there for ODL students in educational institutions. What students need to do is find ways in which they can cope and manage.Swent in Buettner (1990) reported on the results of a study in the state of Oregon where one thousand two hundred and forty five respondents reported the way they handled the tensions and pressures of their tasks. The activities were divided into three major areas; physiological activities, cognitive and psychological activities and interpersonal and organisational activities.

Activities of a physiological type were the most frequent stress-reduction technique (65\%). More than $(85 \%)$ of these respondents used some form of exercise or physical labour, $(22 \%)$ of the respondents indicated coping strategies in the cognitive/ psychological area with more than half of these responses related to separating one's sense from one's environment. The study found a low level (12\%) of reported coping responses characterised as inter personal or organisational management skills. Swent concluded that stress affects each individual differently and a variety of coping techniques should be adapted to that individual.

Barley, Fillos, Kelly in Buettner (1990) in a study conducted in the mid-Atlantic region examined exemplary conventional vocational students' stress and how they coped. They found that these students were more likely to use vocational / recreational skills approaches to coping than physiological or sociopsychological approaches. The study found that these students developed strong stress coping strategies through developed skills. Diederick (1987) identified the significant issues, conflicts and experiences which occurred during the time respondents underwent their first year at institutions. In his study he found out that the subjects were able to cope with stressful events by using the following strategies. They took things slowly, sought psycho-social support from the system, learnt from mistakes, being organised, anticipating problems and kept a calendar. The study also concluded that negative feelings amongst the subjects related to loss of one's previous support system. Recommendations in the study included lesser vice programme opportunities for space and time to be away as important.

Yackel (1998) investigated ways of coping used by male subjects in rural public centres in Saskatchewan. He statistically compared the frequency and intensity of stress. He concluded that there was no relationship between leadership style, stress and the role of coping methods employed. Results from the study indicated that task-oriented subjects and relationship-oriented subjects perceived themselves similarly in terms of total frequency and intensity of stress experience. The study also noted that the choice of coping mechanisms was not based on an individual's broad motivational structure of task or person orientation. Methods of coping are not employed as a response to the specific nature of the stresses experienced but rather as a general response. Yackel (1988) then speculated that the selection of coping methods is governed by reasons such as personal likes and dislikes, past experiences, accessibility, cost, social, acceptability and peer influence.

Puhl (2010) assessed the relationship of demands, ability to cope, and stress in a study of administrators in school subjects in the United Kingdom and States of America .The overall average of the intensity scale indicated a mild to moderate amount of stress. In the area of coping effectiveness, Hierbert and Basserman (1986) found out that subjects saw themselves as coping very effectively with the demands of their tasks. They found no statistically reliable differences on any of the demographic dimensions with the frequency, intensity, and copying effectiveness scales.

Taylor (1986) model of coping has been adopted and used by social workers, teachers, students and administrators when managing stressful events. The model which was further adopted and perfected by Muersing (1996) shows the individual's mental and physical well being and his/her preventive behaviour as the outcome variables of coping. The variables are posited to be the product of mismatch between task demands on one hand and social support influences and individual factors on the other hand (Muersing 1996). The variables in this model are social support, material resources, individual factors, community factors, medical, self-efficacy beliefs, coping responses and lastly coping outcomes, (Taylor 1986; Muersing 1996). Self-efficacy beliefs for coping with the stresses are influenced by factors such as cultural, community factors, the availability and nature 
of the relevant social support, material resources and individual personality factors (Taylor- 1986; Muersing 1996).

This model of coping can be used by ODL students in ZOU Harare as it assumes that social support influences, self-efficacy, beliefs and material resources enhance problem-focused coping. Effective coping generates more social support with better or more material resources, D'cruz (2000) Puhl 2010. In Muersing's view a coping outcome is management of stressful events and even notes that important contextual variables are the availability of social support and material resources for coping. Whereas in Muersing's adaptation of Taylor's model of coping, the issue of social coping and emotional coping are fairly attainable, material or economic coping and medical coping may be difficult for ODL students in developing countries due to scarcity of resources.

The literature review looked at the theoretical framework for this study, which was based on the theory of coping developed by Folkman and Lazarus. Researches on coping mechanisms used by students in other countries were also reviewed.The countries include the United States of America, Sweden and the United Kingdom. It was noted from literature reviewed that coping assumes that social support influences self-efficacy beliefs and enhances problem-focused coping. Many forms of coping mechanisms were identified and some were found to be more effective than others.

\section{Methodology}

This study used the quantitative approach. The approach enabled the researchers to find out the coping mechanisms used and the popularity of the mechanisms among students in ODL at ZOU Harare Region.

\subsection{Research Design}

This study used the descriptive survey method of research in which through a questionnaire, and focus group discussion the respondents were asked to provide information on their perceptions, coping strategies in managing stressful events in ODL at ZOU Harare. The hallmark of the descriptive survey method and focus group discussion is its strength as a tool for investigating the present status of phenomena, Dempsey and Dempsey (1996). The design was therefore relevant to the mode of the study, which investigated the present coping mechanism used by students in ODL at Harare Region in managing stressful events. The study used Harare Region (for convenience)

\subsection{Sampling}

From a population of seventy students who had been identified as performing very well in the four faculties, twenty (ten male and ten female) purposively selected students were used. All the twenty students had more than two years of learning at the ODL institution and some of them had requested postponement or deferment. These were chosen because of the researchers' personal contacts with the Center for Student Management unit within the ODL institution. Purposive sampling afforded the researchers more control over respondents who could provide more -credible and rich information (Denzin and Lincoln 1994).

\subsection{Data Collection Method}

Following rapport building and soliciting of their cooperation, respondents were asked to participate. Open ended questionnaires were issued to the respondents. The questionnaires were completed within an average thirty minutes. Focus group discussion was used to validate data obtained from individual respondents. Data collection took two weeks. Consent was given after assuring the respondents that anonymity of all respondents would be strictly protected by concealing their names and any other identifying information in reports or publications. The letters A, B, C, D, were assigned as codes for the different faculties. Responses to the questions were grouped and analysed. Focus group discussions were used to triangulate the information.

\subsection{Data Collection Tools}

The instrument that was used was the Ways of Coping questionnaire adapted from Lazarus and Folkman (1988). The questionnaire was modified and adapted to fit the ZOU ODL situation. In the original questionnaire there were sixty coping statements which were put on a Likert scale of one to four. The Likert scale was removed in the adapted questionnaire, as effectiveness of the coping mechanism was not being measured. On the coping statements nine were removed as these were not suitable to the ODL Zimbabwe Open University Harare Region environment. The adapted questionnaire was divided into three sections. The first section (A) requested demographic information including years in the programme, number of repeats, postponements and deferments in the four semesters. In section B respondents were asked to think of an event which had occurred to them in the process of their education at the University which was stressful. The 
respondents were asked to describe the event and provide a self - rating of their ability to cope with this stressful event.

In section $\mathrm{C}$ they had to read each coping statement under coping mechanism and indicate by circling the coping statement they had used in response to the stressful event.

Folkman and Lazarus (1988) identified eight coping mechanisms in the "Ways of coping questionnaire".

\subsection{Pilot Study}

A pilot study was done to test the data collection tools and improve their quality and efficiency. The responses were analysed in detail and the following problems were noted. On section A of the questionnaire there was need to include a rating scale using the words effective, and very effective, instead of using the numbers one to ten. On section B there was need to include the responses I prayed, changed or grew as a person. Under section $\mathrm{C}$ there were no changes made.

\subsection{Data Organisation and Analysis}

When all the data was collected, it was read repeatedly. Immersion was done and this allowed the researchers to identify patterns and categories from the data. After collection of data the frequency of use of each coping statement was deducted. Data was placed in eight categories. Coping responses under these eight categories had their frequencies recorded.

The categories were confrontive coping, distancing, self controlling, seeking social support, accepting responsibility, escape avoidance, playful problem solving and positive reappraisal.

Data was presented in frequency tables and illustrated on a histogram. Percentages were used to organise data. Prolonged engagement led the researchers to spend more time putting data into the eight categories. This helped in gaining insight into respondents coping experiences and ensure the rigour of the findings. The frequency of use of each coping statement was found by counting the number of times the respondents used this.

Coping statements with extremely high and low frequency responses were reported. The effectiveness of each coping statements used was noted by checking and recording how they responded to how they viewed their coping mechanisms. In addition the percentage of coping statements used under each coping mechanism was determined and these were compared to find out the most widely used coping mechanisms.

Finally, the number of effective coping mechanisms that were reported by ZOU Harare Region ODL students was determined by calculating the frequency to which respondents selected.

\section{Findings}

Data was analysed using both the descriptive and comparative statistics. Students from all faculties reported that the methods they used were quite effective to cope with stressful events.

\subsection{Coping Mechanisms used by ODL students at ZOU Harare Region}

Fig 1 Coping mechanisms as used by students

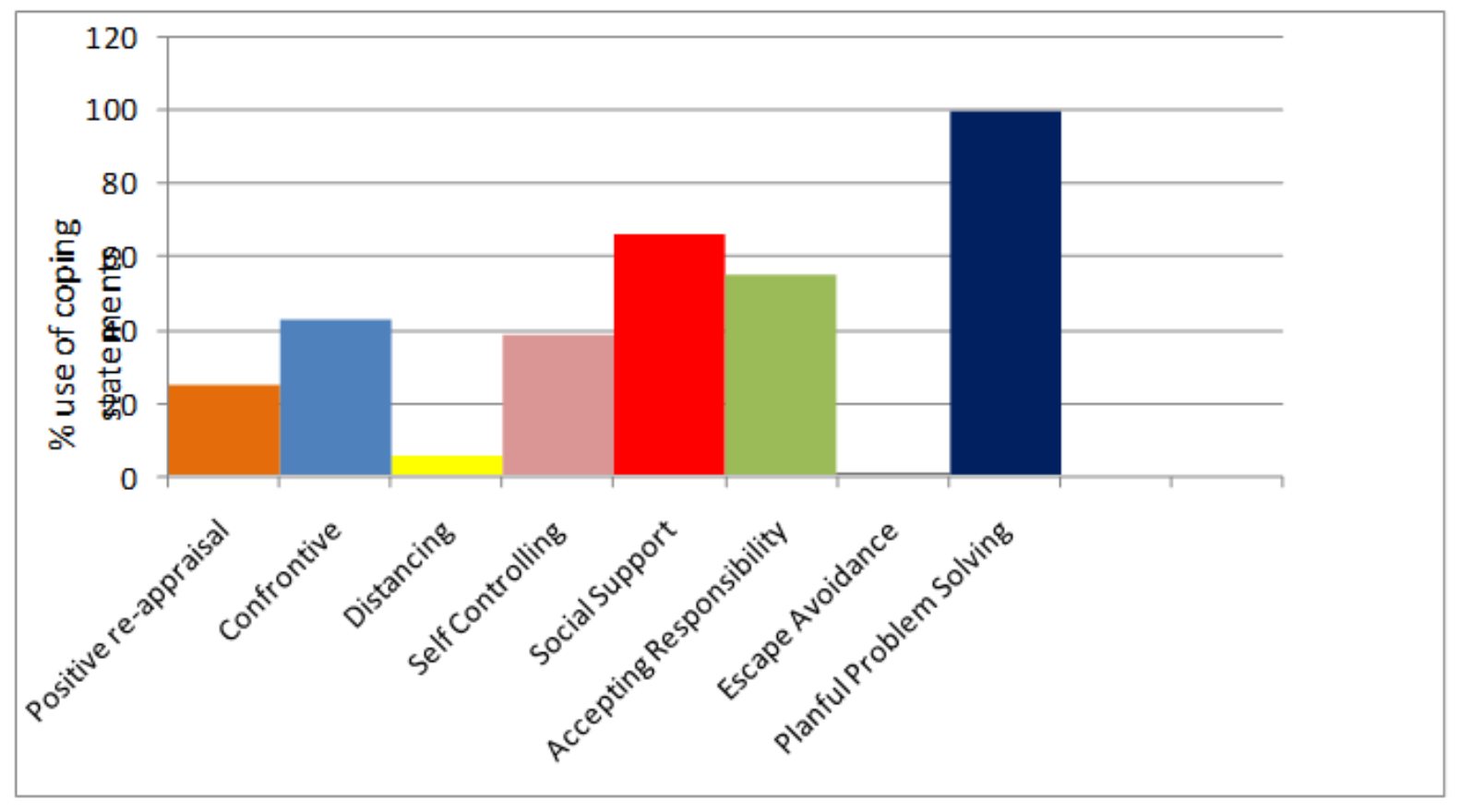


There were eight coping mechanisms, which students used in response to stressful events in their education. The coping mechanisms that were used were confrontive coping, distancing, self-controlling, seeking social support, accepting responsibility, escape-avoidance, planful problem solving and positive re-appraisal. Each coping mechanism had a number of different coping statements, which students could use to deal with the stressful event.

Planful problem solving was the highest frequently used coping mechanism. This is a strategy that protects self esteem. Students would like to be recognised as organised. Whether the students are really organised or not is subject to further research.Escape-avoidance was the least used coping mechanism. This mechanism shows low confidence in ability to cope with stressful situations. The population from which the sample was selected comprised high performing students who are generally confident.

Students from all faculties reported that the methods they used were quite effective to cope with stressful events.

The findings noted that all the students had used some form of coping mechanism during the more than two years stay at the institution. All respondents were able to cope with stressful events that occurred during their education with the aid of some form of support system. Respondents recorded wide use of six of the eight coping mechanisms. Distancing and escape-avoidance were significantly unpopular. Lazarus and Folkman (1984) found out that episodic coping measures deal with the strategies individuals actually use in a particular stressful situation. Results obtained indicated the four coping mechanisms planful problem solving, accepting responsibility, seeking social support and confrontive coping all fall under this category.

In literature reviewed on studies carried out in the mid-Atlantic region, results indicated strong stress coping strategies through management skills. This is in line with the results of this study were planful problem solving was the most used coping mechanism.Muersing's (1996) model of coping which was adopted from Taylor (1986) depicts itself in the results of this research. The model shows the individual's mental and physical well-being and his/her preventive behaviour as the outcome variables of coping. The results obtained in the study show that deferment and postponement were limited because of the social support given by student management office and administrators which concurs with this model. In the faculty of social sciences, were the students did courses with components of psycho-social support, it was noted that there was a significant relationship with the type of coping mechanism used. Most of them used, "accepting responsibility and planful coping".

The findings about variations in various coping mechanisms are consistent with the findings of other studies identified in the literature review. Swent in Buettner (1990) found in his study that sixty-six percent of the respondents used physiological stress reduction activities. Twenty two percent used cognitive/ psychological/ organisational activities. He concluded that a variety of coping mechanisms are needed to assist individuals. These results are similar to those found in this study were respondents used a variety of coping mechanisms.

Planful problem solving mechanism was the most popular coping mechanism used. It describes aggressive efforts to alter or change the stressful situation and suggests some degree of hostility and risk taking. This could be as result of the need to acquire higher qualifications and get promotion at work. According to literature reviewed Muersing's(1996) model of coping, social support and self controlling also ranked near the top in use, is consistent with his view that model for coping can be used by individuals assume that social support influences self efficiency beliefs and enhances self efficiency belief and enhances problem focused coping. In Muersing's view coping outcome is management of stressful events influenced by the factors such as cultural, community and administration structure. One function of the student management department at the Region was to provide support to the Regional Director in helping students cope with stressful events. Respondents all reported seeking social support.

Escape-avoidance was at the bottom in use. In Muersing's (1996) coping model self-efficiency beliefs for coping need individuals to adopt caring attitudes towards others. In Taylor's view it would be less likely that an individual would avoid a stressful situation since this would indicate that one is not in control.

\section{Summary}

The purpose of the study was to determine the coping mechanisms used by ZOU Harare Region ODL students. All respondents reported having used some form of coping mechanism in handling stressful events. The students self rated their ability to deal with stressful events as quite effective.Planful problem solving was the most used coping mechanism and escape avoidance was the least used coping mechanism. Students reported the use of six of the eight coping mechanisms. These were planful problem solving, self controlling, seeking social support, positive reappraisal, accepting responsibility, confrontive coping. The other two distancing and escape avoidance were least used. 


\section{Conclusion}

The conclusion presented has come from the evidence from the findings. Students from the applied social sciences were found to manage stress more effectively. This could be because of their exposure to counseling and psychology courses. It is difficult to measure the use of coping mechanisms. It is likely that during any stressful event or situation in the institution, a great number of factors are involved making it difficult to pin point the actual coping mechanism used. In most cases a combination of coping mechanisms is used. Even the students may not have been aware that they were using combinations of coping mechanisms.. It is concluded that ZOU ODL students in Harare use different types of coping mechanisms during their education in response to stressful events. Planful problem solving was reported to be the most used coping mechanism.

\section{Recommendations}

As a result of this study, some areas of concern arose. The researchers would like to make the following recommendations. These are addressed to the Ministry of Higher Education and ODL institutions:

- Students should be taught how to recognise, analyse, and cope with stressful events. This could be done by introducing courses with elements of psycho-social support.

- There is need for institutions to expand the existing formal support system by increasing personnel in the Center for Student Management and capacitate all university staff with skills to support students with challenges.

- Institutions should minimize all inadequacies that stress the students by providing enough learning materials and communication channels that reach all students so that they are well informed about the goings on in the institution.

- Students should be informed about support systems available in the communities where they can go and receive assistance.

- Further research is required to establish the link between demographic data and choice of coping mechanism.

\section{References}

[1] A .Van Dorp,T. Monteros, Challenges for Open and Distance Learning in Post 2010.e learning ed No 18,February 2010.issn1887$1542,2010$.

[2] L.Baider, C Cooper and A.K.De Nour, Cancer and the Family, (Chichester: John Wiley 1996).

[3] P.D'Cruz, Family Care in Stressful Situations, Journal on Support Systems, 2002

[4] R Chimedza, New Students' Orientation Handbook (Harare: Zimbabwe Open University, undated).

[5] S.Folkman and R.S.Lazarus, An Analysis of Coping in a Middle-aged Community sample. Journal of Health and Social Behaviour, 1988 p $210-240$.

[6] R.Muersing, Measures and concepts of coping and social support, (New York: Macmillan 1996)

[7] R.Puhl and K.D.Brownell, Ways of coping with obesity stigma: Review and conceptual analysis Journal of Psychology 4, 2003, 5378

[8] R.Buettner, A Report in Coping Mechanisms Used by Rural Administrators 1990 pp (1-20)

[9] R.S.Lazarus and S.Folkman, Stress Appraisal and Coping, (NewYork: Springer Publishing, 1988)

[10] S.Taylor, Coping with Stress, (New York: Macmillan 1986).

[11] EUA, Financially, Sustainable Universities towards full costing in European Universities, An EUA Report .European Universities Association.2008.

[12] G.Geser, Open Educational Practices and Resources, (OLCOS, Roadmap 2010, 2007)

[13] Kaufman, State of Entreneurship Address. (Washington DC: National Press Club January 19 2010)

[14] A.M. Diedrick, The Transition from Teacher to Administrator. Report presented at the Annual Meeting of the American Educational Research Association, Washington DC 1987.

[15] Hiebert and Basserman (1986) Coping with job demands and avoiding stress. Journal of the Canadian Administrator 26 Volume 1 1986.

[16] S.Dempsey and P.Dempsey, Research Processes used in Nursing Research Qualitative Health Research. (London: Basil Blackwell, 1996).

[17] N.Denzin and Y.Lincoln, eds Handbook of Qualitative Research,(Thousand Oaks, CA: Sage,1994) 